\title{
Hepatitis C virus eradication on glycemic control and insulin resistance
}

\author{
Manuela Maria de Lima Carvalhal ${ }^{*}$ * (1), Jeane Lorena Lima Dias ${ }^{1}$ (1), \\ Daniela Lopes Gomes ${ }^{1}$ 미 , Juarez Antônio Simões Quaresma
}

\section{SUMMARY}

OBJECTIVE: To review data regarding the effects of hepatitis $C$ virus eradication on glycemic control and insulin resistance. METHODS: This is an integrative literature review, carried out in the PubMed, SciELO, and Lilacs databases. Studies published in the past five years that were fully available, written in English or Portuguese, and have addressed the effects of eradication of the hepatitis $C$ virus on glycemic control and insulin resistance were selected.

RESULTS: Nine studies were selected. Among the results found, it was observed that there is no consensus on the effects of viral eradication on glycemic control and IR, as some authors show an eventual improvement in insulin resistance and glycemic control, while other studies indicate that there are no significant differences between the parameters evaluated after viral eradication.

CONCLUSIONS: Although there is a relationship between hepatitis $C$ virus infection and the development of insulin resistance and type 2 diabetes mellitus and recent advances in research, it was observed that there is no consensus on improving insulin resistance and glycemic control after antiviral treatment, probably due to methodological differences between studies. However, it emphasizes the need to guide people diagnosed with hepatitis C, regarding changes in lifestyle, encouragement of multidisciplinary monitoring, and control of other risk factors.

KEYWORDS: Hepatitis C. Insulin resistance. Diabetes mellitus.

\section{INTRODUCTION}

According to the Guidelines of the Brazilian Society of Diabetes ${ }^{1}$, there is an increased risk of type 2 diabetes mellitus (T2DM) and insulin resistance (IR) in patients with chronic viral hepatitis, with T2DM being considered one of the most common causes of extrahepatic disease in hepatitis $\mathrm{C}$ virus (HCV) infection.

Serfaty ${ }^{2}$ reported that the prevalence of T2DM can range from $13.6-67.4 \%$ in cases of HCV infection, values higher than those observed for individuals with other chronic liver diseases. Husseim et al. ${ }^{3}$ observed a high prevalence of T2DM associated with HCV infection and an increased risk of developing T2DM in individuals with risk factors for metabolic syndrome in the presence of viral infection.
Shawky et al. ${ }^{4}$ recruited 60 non-diabetic Egyptian patients with chronic HCV infection to assess IR. Participants were divided into three groups as follows: Group 1 included 30 patients with chronic HCV infection without cirrhosis, Group 2 included 30 patients with chronic HCV infection and liver cirrhosis, and Group 3 included 30 control volunteers. Fasting glucose and insulin levels were found to be significantly higher in Group 2 than those in Groups 1 and 3.

$\mathrm{HCV}$ is able to promote IR through several pathogenic pathways, including direct inhibition of intracellular insulin signaling, oxidative stress, activation of inflammatory pathways, modulation of incretins, and dysfunction of pancreatic $\beta$ cells. The virus can impair the insulin signaling

1Universidade Federal do Pará - Belém (PA), Brazil.

*Corresponding author: manuela.carvalhall@gmail.com

Conflicts of interest: the authors declare there is no conflicts of interest. Funding: none.

Received on August 05, 2021. Accepted on September 17, 2021. 
pathway through several mechanisms, among which are a stimulus for the production of tumor necrosis factor-alpha (TNF- $\alpha$ ), in which high levels in patients with HCV are directly associated with the levels of HOMA-IR and the degree of steatosis, and the serine phosphorylation of insulin receptors ${ }^{1,5}$.

T2DM is related to the development of implications and worsens the situation of individuals with hepatitis $\mathrm{C}$ in all stages of the disease, even after liver transplantation. The diverse effects related to T2DM are decreased response to antiviral treatment, rapid progression from fibrosis to cirrhosis, and greater chances of developing hepatocellular carcinoma, which may lead to a decrease in the survival rate ${ }^{6,7}$.

Although it has already been shown that direct antiviral agents (DAAs) help to eradicate $\mathrm{HCV}$ in most patients, there is not much information about viral eradication in hepatic and extrahepatic damage ${ }^{8}$. Therefore, knowing the relationship between HCV infection and the development of IR and T2DM, and due to the controversies of studies in individuals who underwent antiviral treatment, the purpose of this integrative review was to collect data on the effects of HCV eradication on glycemic control and in IR.

\section{METHODS}

This is an integrative review, carried out from April to June 2021.

The guiding question was elaborated using the PICO strategy, as proposed by Santos et al. ${ }^{9}$, considering $\mathrm{P}$ - patients with hepatitis C; I - use of antivirals; C - not applicable to this study; and $\mathrm{O}$ - improvement in glycemic control and IR after viral eradication. Thus, the design of this study arose from the following question: in patients with hepatitis $\mathrm{C}$, does viral eradication improve glycemic control and IR?

PubMed, SciELO, and Lilacs databases were used with the following indexed descriptors and their respective synonymies of Medical Subject Headings (MeSH), as well as the following connectives:

1. Hepatitis and;

2. Diabetes mellitus and;

3. Insulin resistance.

For selection, initially, there was the identification stage, with the reading of the publication titles; then, in the screening stage, the abstracts were read to exclude studies that did not meet the research purpose and duplicate publications; at the eligibility stage, the articles were read in full to select those that would be included in this review.

As inclusion criteria, studies published in the past five years that were fully available, written in English or Portuguese, and have addressed the effects of eradication of the HCV on glycemic control and IR were selected. Regarding exclusion criteria, literature review studies, case reports, letters, and editorials were excluded.

\section{RESULTS}

Figure 1 shows the stages for selecting the articles. In total, 65 studies were found, of which nine were included in this review (Table 1).

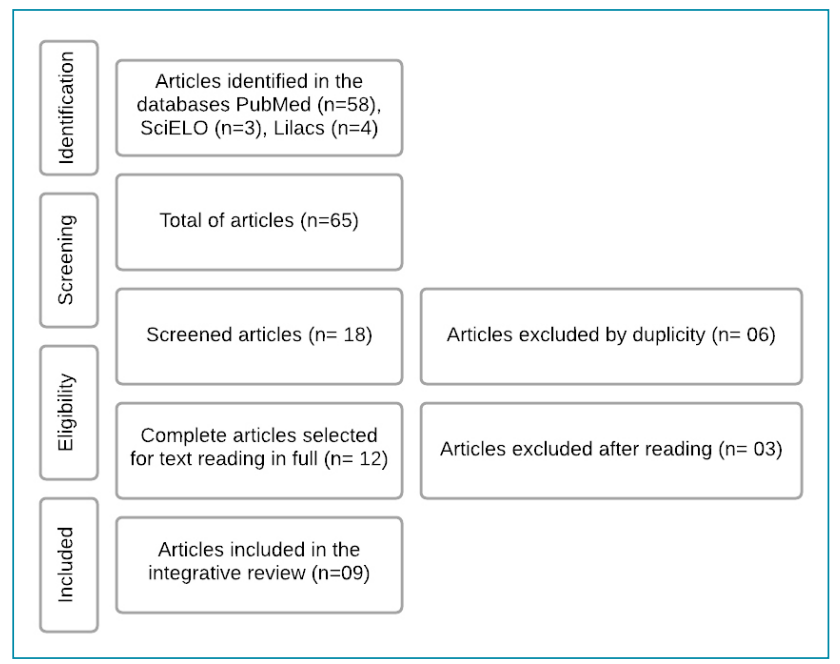

Figure 1. Eligibility flowchart.

Table 1. Study type and sample size of the selected articles.

\begin{tabular}{|c|c|c|}
\hline Author; Country & Study type & Sample size \\
\hline $\begin{array}{l}\text { Andrade et al. } .^{10} \\
\text { Brazil }\end{array}$ & Prospective & 150 patients \\
\hline $\begin{array}{l}\text { Ciancio et al. }{ }^{12} \text {; } \\
\text { Italy }\end{array}$ & Case-control & 122 patients \\
\hline $\begin{array}{l}\text { Gastaldi et al. }{ }^{14} \text {; } \\
\text { Switzerland }\end{array}$ & Intervention & 17 patients \\
\hline $\begin{array}{l}\text { Gualerzi et al. }{ }^{13} \text {; } \\
\text { Italy }\end{array}$ & Prospective cohort & 82 patients \\
\hline $\begin{array}{l}\text { Lanini et al. } \\
\text { London }\end{array}$ & Historical cohort & 205 patients \\
\hline $\begin{array}{l}\text { Laurito et al. }{ }^{11} \text {; } \\
\text { Brazil }\end{array}$ & $\begin{array}{l}\text { Multicentric, } \\
\text { retrospective }\end{array}$ & 200 patients \\
\hline $\begin{array}{l}\text { Li et al. }{ }^{15} \text {; } \\
\text { the United States }\end{array}$ & Cohort & 5,127 patients \\
\hline $\begin{array}{l}\text { Stine et al. }{ }^{17} \\
\text { the United States }\end{array}$ & $\begin{array}{l}\text { Retrospective } \\
\text { cohort }\end{array}$ & 175 patients \\
\hline $\begin{array}{l}\text { Strauhs-Nitsch } \\
\text { et al. }{ }^{16} ; \text { Brazil }\end{array}$ & Prospective & 75 patients \\
\hline
\end{tabular}




\section{DISCUSSION}

\section{Viral eradication effects on glycemic control and insulin resistance}

Lanini et al. ${ }^{8}$ conducted a cohort study in patients with HCVrelated liver diseases and provided evidence that DAA therapy can have positive effects on glycemic control in patients with chronic hepatitis $\mathrm{C}$ even when liver cirrhosis is already established. In addition, metabolic improvement may still persist after the end of therapy. However, despite the improvements, blood glucose remained higher in patients with diabetes compared to those without diabetes, indicating that $\mathrm{HCV}$ is not the only factor involved in the pathogenesis of diabetes.

Andrade et al. ${ }^{10}$ aimed to evaluate the HOMA-IR in patients with hepatitis $C$ treated with DAAs in the sustained virological response (SVR) and observed an increase in mean glucose in the general study population (baseline: $100.65 \pm 19.7$ versus after treatment: 102.36 \pm 24.52 ) and in the HOMA-IR (baseline: 3.69 2.99 versus after treatment: $3.72 \pm 3.26$ ), but there was a decrease in insulin levels (baseline: $14.46 \pm 10.26$ versus after treatment: $14.03 \pm 10.32$ ). Regarding the Delta HOMA-IR, a negative value was observed in the evaluation after drug treatment, but there was no significant difference. When excluding diabetic patients and those with normal HOMA-IR values $(<2.5)$, the mean values of glucose, insulin, HOMA-IR, and Delta HOMA decreased after treatment, the latter with a significant reduction $(\mathrm{p}=0.02)$.

Laurito et al. ${ }^{11}$ evaluated the impact of IR on SVR in 200 patients with HCV genotype 3 treated with peg-interferon plus ribavirin. Lower IR values were observed in individuals with SVR when compared to those without SVR (2.82 \pm 2 versus 3.54 2 .1; $\mathrm{p}=0.004)$. When the univariate analysis was performed, patients with HOMA-IR $\geq 2.5$ were 2.6 times less likely to achieve SVR (OR 2.63, 95\%CI 1.336-5.175, p=0.005). However, in the multivariate analysis, the HOMA-IR did not reach significance as a predictor of SVR, observing an association only with age and tendency with advanced fibrosis.

Ciancio et al. ${ }^{12}$ found that SVR induced significant improvements in fasting glucose and glycated hemoglobin rates in diabetic patients with HCV, thus aiding in glycemic control, despite the observed weight gain.

Gualerzi et al. ${ }^{13}$ observed an improvement in the parameters assessed for glucose metabolism in individuals with HCV soon after antiviral treatment. A significant decrease in glucose and insulin levels was found, leading to a reduction in HOMA-IR values (pretreatment: 3.42 [2.66-5.38]; post-treatment: 2.80 [1.78-3.95]; $\mathrm{p}<0.001$ ), increase in insulin sensitivity (pre: 0.49 [0.26-0.75]; post: 0.64 [0.42-0.91]; $\mathrm{p}<0.001$ ), and a significant reduction in insulin secretion (pre: 1363 [959-1730]; post: 1264 [976-1588]; $\mathrm{p}=0.027)$.
Evaluating interferon-free antiviral therapy (IFN $\alpha)$ in improving liver and peripheral insulin sensitivity associated with HCV, Gastaldi et al. ${ }^{14}$ found that complete suppression of virus replication induced by an IFN $\alpha$-free regimen in lean patients with chronic hepatitis $\mathrm{C}$ without fibrosis improves extrahepatic (but not hepatic) insulin sensitivity.

Li et al. ${ }^{15}$ evaluated the impact of HCV treatment response in the presence of cirrhosis and other factors on the incidence of T2DM. The authors found that SVR reduced the risk of T2DM by $21 \%$. Therefore, the incidence of diabetes was significantly lower among patients who achieved SVR than those who failed treatment, demonstrating that successful treatment significantly reduces the incidence of T2DM. In addition, patients with a body mass index (BMI) $\geq 30 \mathrm{~kg} / \mathrm{m}^{2}$ had an almost four times higher risk of T2DM than patients with a BMI $<25 \mathrm{~kg} /$ $\mathrm{m}^{2}$, and individuals with cirrhosis had a 1.5 times higher risk of T2DM than those without cirrhosis. Also, there is a higher risk for T2DM in patients of African-American, Asian, Native American, or Pacific Islander origin.

In contrast, when comparing the HOMA-IR results of 75 patients with chronic hepatitis $\mathrm{C}$ before and after treatment with DAA, Strauhs-Nitsh et al. ${ }^{16}$ observed a total of $41.3 \%$ of patients with IR before treatment and 52\% after the end of medication, with no statistically significant difference $(\mathrm{p}=0.077)$. When diabetic patients were excluded, there was also no statistical change in the HOMA-IR results before and after the SVR ( $\mathrm{p}=0.497)$, that is, there was no improvement in the IR according to the HOMA-IR after obtaining the SVR.

Stine et al. ${ }^{17}$ investigated whether treatment with DAA leads to improved post-treatment IR and observed that despite chronic $\mathrm{HCV}$ being associated with increased IR, there was no significant difference $(\mathrm{p}=0.268)$ between the level of glycated hemoglobin (HbAlc) in the pretreatment $(7.36 \mathrm{mg} / \mathrm{dL}, 95 \% \mathrm{CI} 6.55-8.16)$ and post-treatment $(7.11 \mathrm{mg} / \mathrm{dL}, 95 \% \mathrm{CI} 6.34-7.88)$ of diabetic individuals with and without cirrhosis. In addition, $23.1 \%$ were taking insulin therapy in pretreatment, compared to $42.3 \%$ in post-treatment, and $53.8 \%$ were taking oral T2DM medications before treatment, compared with $57.7 \%$ after completion, but there was no statistically significant difference. Thus, the authors emphasized that HbA1c was not affected by viral eradication; however, this result can be attributed to the clinical management of diabetes and hyperglycemia with pharmacological therapy, since increasing doses of antihyperglycemic drug use were observed, suggesting the need for long-term studies to comprehend the relationship between viral eradication and insulin metabolism.

This study has limitations. First, methodological differences for the assessment of IR and glycemic changes made it difficult to compare the results. Second, there was lack of a cutoff point to classify the presence of IR by the HOMA-IR. Furthermore, the 
samples varied in terms of fibrosis staging, which also interfered with the results observed. Thus, new intervention studies are suggested to identify whether there is improvement in IR and glycemic control in patients after the eradication of the HCV, emphasizing the need to establish a methodological standard in future research.

\section{CONCLUSIONS}

Although there is a relationship between HCV infection and the development of IR and T2DM and recent advances in research, it was observed that there is no consensus on the improvement of IR and glycemic control after antiviral treatment, possibly due to methodological differences between the studies. However, it emphasizes the need to guide people diagnosed with hepatitis $\mathrm{C}$ regarding lifestyle changes, in addition to encouraging multidisciplinary monitoring with periodic biochemical tests and control of other risk factors that may interfere with glycemic control.

\section{AUTHORS" CONTRIBUTIONS}

MMLC: Conceptualization, Data curation, Formal Analysis, Investigation, Methodology, Visualization, Writing - original draft, Writing - review \& editing. JLLD: Conceptualization, Data curation, Formal Analysis, Investigation, Methodology, Visualization, Writing - original draft, Writing - review \& editing. DLG: Conceptualization, Methodology, Supervision, Writing - review \& editing. JASQ: Conceptualization, Methodology, Supervision, Writing - review \& editing.

\section{REFERENCES}

1. Sociedade Brasileira de Diabetes. Diretrizes Sociedade Brasileira de Diabetes 2019-2020 [Internet]. São Paulo: Clanad Editora Científica; 2019. p. 1-490. [cited on Nov 8, 2020]. Available from: https://www.diabetes.org.br/profissionais/images/ DIRETRIZES-COMPLETA-2019-2020.pdf

2. Serfaty L. Metabolic manifestations of hepatitis c virus: diabetes mellitus, dyslipidemia. Clin Liver Dis. 2017;21(3):475-86. http:// doi.org/10.1016/j.cld.2017.03.004

3. Hussein HA, Allam AS, Moaty ASA. Evaluation of glycated haemoglobin (hba1c) level in type 2 diabetic chronic hcv non-cirrhotic treatment-naïve Egyptian patients eradicated with sofosbuvir plus daclatasvir. Curr Diabetes Rev. 2020;16(2):16570. http://doi.org/10.2174/1573399815666190531091128

4. Shawky MA, Mohammed AQ, Hassan AM, Ali BH, Moustafa $\mathrm{HM}$. Insulin resistance in nondiabetic Egyptian patients with chronic hepatitis C virus. Rev Gastroenterol Mex (Engl Ed). 2020;85(2):173-9. http://doi.org/10.1016/j.rgmxen.2019.05.007

5. Vanni E, Bugianesi E, Saracco G. Treatment of type 2 diabetes mellitus by viral eradication in chronic hepatitis C: myth or reality? Dig Liver Dis. 2016;48(2):105-11. http://doi. org/10.1016/j.dld.2015.10.016

6. García-Compeán D, González-González JA, Lavalle-González FJ, González-Moreno El, Villarreal-Pérez JZ, Maldonado-Garza HJ. Hepatogenous diabetes: is it a neglected condition in chronic liver disease? World J Gastroenterol. 2016;22(10):2869-74. http://doi.org/10.3748/wjg.v22.i10.2869

7. Pattullo V, Heathcote J. Hepatitis $C$ and diabetes: one treatment for two diseases? Liver Int. 2010;30(3):356-64. http://doi. org/10.1111/j.1478-3231.2009.02185.x

8. Lanini S, Bartolini B, Taibi C, Agresta A, Garbuglia AR, Montaldo C, et al. Early improvement of glycaemic control after virus clearance in patients with chronic hepatitis $C$ and severe liver fibrosis: a cohort study. New Microbiol. 2019;42(3):139-44. PMID: 31305933

9. Santos CMC, Pimenta CAM, Nobre MRC. A estratégia PICO para a construção da pergunta de pesquisa e busca de evidências. Rev Latino-Am Enfermagem. 2007;15(3):508-11. https://doi.org/10.1590/S0104-11692007000300023
10. Andrade VGD, Yamashiro FDS, Oliveira CV, Moreira A, Winckler FC, Silva GF. Insulin resistance reduction after sustained virological response with direct acting antiviral: not every population improves. Arq Gastroenterol. 2018;55(3):274-8. http://doi.org/10.1590/s0004-2803.201800000-69

11. Laurito MP, Silva GF, Cheinquer $H$, Sharma R, Verna $E$, Parise ER. Does insulin resistance impair the virological response to peginterferon/ribavirin in chronic hepatitis $C$ genotype 3 patients? Arq Gastroenterol. 2018;55(2):179-83. https://doi. org/10.1590/S0004-2803.201800000-32

12. Ciancio A, Bosio R, Bo S, Pellegrini M, Sacco M, Vogliotti E, et al. Significant improvement of glycemic control in diabetic patients with HCV infection responding to direct-acting antiviral agents. J Med Virol. 2018;90(2):320-7. http://doi.org/10.1002/jmv.24954

13. Gualerzi A, Bellan M, Smirne C, Tran Minh M, Rigamonti C, Burlone ME, et al. Improvement of insulin sensitivity in diabetic and non diabetic patients with chronic hepatitis $C$ treated with direct antiviral agents. PLoS One. 2018;13(12):e0209216. https://doi.org/10.1371/journal.pone.0209216

14. Gastaldi G, Gomes D, Schneiter P, Montet X, Tappy L, Clément $S$, et al. Treatment with direct-acting antivirals improves peripheral insulin sensitivity in non-diabetic, lean chronic hepatitis C patients. PLoS One. 2019;14(6):e0217751. https:// doi.org/10.1371/journal.pone.0217751

15. Li J, Zhang T, Gordon SC, Rupp LB, Trudeau S, Holmberg SD, et al. Impact of sustained virologic response on risk of type 2 diabetes among hepatitis $C$ patients in the United States. J Viral Hepat. 2018;25(8):952-8 . https://doi.org/10.1111/jvh.12887

16. Strauhs-Nitsch L, Campiolo MF, Morsoletto DBG, Pissaia A, Ivantes CAP. Curing hepatitis $C$ with the new direct acting antivirals did not improve insulin resistance after one year. Arq Gastroenterol. 2020;57(3):267-71. https://doi.org/10.1590/ S0004-2803.202000000-50

17. Stine JG, Wynter JA, Niccum B, Kelly V, Caldwell SH, Shah NL. Effect of treatment with direct acting antiviral on glycemic control in patients with diabetes mellitus and chronic hepatitis C. Ann Hepatol. 2017;16(2):215-20. https://doi.org/10.5604/16652681.1231581 